\title{
CANHESTRO E DeterIORADO: AS REALIDADES DO REALISMO*
}

IAN WATT

S

into-me, é claro, muito lisonjeado com o convite para vir aqui, e por diversos motivos. ${ }^{1}$ Como disse Horace Walpole sobre o sucesso inesperado de O castelo de Otranto, "É delicioso entrar na moda" (carta para George Augustus Selwyn, 2 de dezembro de 1765). ${ }^{2}$ É particularmente delicioso porque empresta credibilidade à hipótese de minha contínua sobrevivência, de modo nenhum universalmente aceita: há pouco tempo encetei uma conversa com um aluno de Berkeley e quando, ao ir embora, revelei meu nome, ele respondeu, perplexo: "Oh, achei que o senhor tivesse morrido". Uma terceira razão, sem dúvida, é que eu não posso alegar que desconheça o que Johnson disse sobre Richardson: que ele "não se contentava em navegar tranquilamente pelas águas da fama sem querer provar o gosto da espuma produzida a cada remada". ${ }^{3}$ Minha dificuldade inicial em decidir se devia vir e, se viesse, sobre o que falaria, em parte derivou de um sentimento de decoro que me dizia que eu mesmo não deveria ser visto agitando as águas da reputação; e, contudo, foi justamente isso o que Paul Hunter me pediu

* Como costuma ocorrer com os títulos de Watt, a tradução de "Flat-footed and Fly-blown: The Realities of Realism" é complicada. Os termos "flat-footed" (canhestro) e "fly-blown" (deteriorado) não encontram um equivalente satisfatório em nossa língua; respectivamente, ao pé da letra querem dizer "pé chato" e, portanto, algo desajeitado, gauche, e "infestado de vermes ou lêndeas", ou seja, corrompido ou bichado. Optei pelos termos ao mesmo tempo fiéis e que permitem os vários empregos que eles assumem no decorrer no texto. A tradução deste artigo recebeu o valioso préstimo da professora Sandra Guardini T. Vasconcelos, que contribuiu com inúmeras sugestões. Sugiro a leitura do artigo da autora, "Ian Watt e a figuração do real", que está neste número da Literatura e sociedade. (N. do T.) Tradução de Marcelo Pen Parreira (DTLLC - USP)

${ }^{1}$ Watt pronunciou esta palestra em uma sessão plenária durante o quarto encontro anual da Southeastern American Society for Eighteenth-Century Studies, da University of Alabama, em Tuscaloosa, em 12 de março de 1978. Foi publicada em conjunto pela Stanford Humanities Review e pela Eighteenth-Century Fiction, com permissão do Department of Special Collections, das Stanford University Libraries. (N. do E.)

${ }^{2}$ Letters of Horace Walpole, ed. Mrs Paget Toynbee, Oxford, Clarendon Press, 1904, 15v., v.6, p. 367.

${ }^{3}$ Ian Watt, A ascensão do romance: estudos sobre Defoe, Richardson e Fielding, São Paulo, Companhia das Letras, 1996, p. 226. Aqui e em outras referências ao livro, vali-me dessa edição, cuja tradução é de Hildegard Feist. O original de Watt, no entanto, é The Rise of the Novel: Studies in Defoe, Richardson, and Fielding, Berkeley, University of California Press, 1957, p. 260. (N. do T.) 
para fazer. A dificuldade c ombina com o fato de que não queria repetir uma transgressão anteriormente aceita nessa linha da autoadulação, um ensaio chamado "Serious Reflections on The Rise of the Novel".

Títulos que começam com "na direção a" sempre me fizeram perguntar: "Por que ele não espera chegar lá? Quem sabe assim saberia se há algo ali que valha a pena apresentar". Em todo caso os senhores não devem esperar nenhuma apresentação minha sobre essa vasta abstração, a "Poética da ficção". Pois o prosaico "canhestro" de meu título decerto sou eu mesmo; e eu continuo a percorrer os caminhos "deteriorados" do "realismo". Imaginei que um meio razoavelmente decoroso de cumprir meu dever seria evitar os rumos já tomados, ou muito trilhados por outras pessoas, e fornecer um relato biográfico de como nasceram alguns dos elementos menos obviamente prosaicos de A ascensão do romance, sobretudo pela influência da tradição intelectual alemã, a menos mundana de todas as formas de pensamento. Assim, ainda permanecendo no exterior, quero examinar rapidamente como as diversas traduções estrangeiras e subsequentes recepções do que eu normalmente imagino ser $A$ ascensão do romance chamaram a atenção para algumas de suas implicações ideológicas mais amplas e menos observadas. Enfim, após uma escala em Paris, tomaremos o rumo de casa para que eu dê minha opinião sobre o status representacional da ficção e, com maior ênfase, sobre a necessidade do realismo na crítica literária.

\section{Os três períodos da composição: tese}

Ao relembrar o processo de composição de A ascensão do romance, exultei quando descobri um padrão verdadeiramente hegeliano de tese, antítese e síntese.

Em 1938, o tópico registrado de minha tese de doutorado era "O romance e seu leitor: 1719-1754". O título reflete algo da atmosfera intelectual de Cambridge no final dos anos 1930. Havia o positivismo lógico. Alguns de meus amigos passavam um bom tempo esperando alguém usar a palavra "por quê?" para poder retrucar: "Mas você deveria saber: as únicas perguntas verdadeiras começam com como". Meu tópico de pesquisa desconsiderava por completo os porquês, admitia o fenômeno mais ou menos publicamente reconhecido do "nascimento do romance" e procurava estudar apenas o "como". Por trás de minha abordagem havia o empirismo e o moralismo arraigado da tradição inglesa - especialmente a de Cambridge. Em especial, havia a crítica do leitor do Practical Criticism (1929), de I. A. Richards, certamente o texto mais influente no que dizia respeito à faculdade de Inglês de Cambridge; e, não menos importante, a combinação da perspectiva histórica e moral dos dois Leavis: F. R. Leavis havia escrito uma tese histórica sobre o meio cultural de Addison e Q. D. Leavis publicado Fiction and the Reading Public em 1932. O principal pressuposto era o de que o passado constituíra uma longa idade de ouro, com uma harmoniosa e frutífera relação entre autor e público;

\footnotetext{
${ }^{4}$ Ian Watt, "Serious Reflections on The Rise of the Novel", The Novel: A Forum on Fiction 1 (1968), p. 205-18; reeditada em Towards a Poetics of Fiction: Essays from "Novel: A Forum on Fiction 1967-1976”, ed. Mark Spilka, Bloomington, Indiana University Press, 1977, p. 90-103.
} 
mas, em seguida, a indústria, os meios de comunicação de massa, o mercantilismo filisteu e a decadência metropolitana produziram a situação da "civilização de massa e da civilização da minoria", contra a qual apenas Cambridge e a Scrutiny se insurgiram. O marxismo foi outra influência primordial sobre o meu pensamento em 1938; e essa influência representou de várias maneiras um surpreendente complemento às outras. A visão materialista do marxismo se ajustou com grande parte da tradição empírica e positivista da academia; e, como ela relacionava literatura e sociedade e via como um declínio catastrófico a situação cultural contemporânea, havia um entendimento substancial entre a crítica comunista e a posição dos dois Leavis. Isso fica bastante claro na obra de meu amigo e contemporâneo Arnold Kettle. O misto de orientação marxista e dos Leavis de sua inestimável Introduction to the English Novel (1951), por exemplo, hoje parece extraordinariamente peculiar.

\section{Antítese: 1946-1948}

Meu próprio tema constituía uma vergonhosa exceção no que se referia aos Leavis e aos marxistas, já que era razoavelmente óbvio que o romance era uma forma literária que não havia ficado pior à medida que nos aproximávamos do presente. Mas, naquela época - 1939 -, eu estava um pouco preocupado com essas dificuldades; obviamente havia problemas muito mais graves pela frente. A guerra começou em setembro. Quando ela terminou e eu fui dispensado sete anos mais tarde na primavera de 1946, me vi sem nenhuma ideia definitiva sobre o que fazer em seguida. Por ter ficado prisioneiro por três anos e meio, eu havia acumulado a maior parte do soldo e mais de meio ano de licença e, quando pensava seriamente no que iria fazer quando tudo terminasse, hoje recordo que a ideia mais conclusiva que eu tinha era a de entrar para o ramo dos vinhos. Mas fui poupado para um destino pior do que o da riqueza e de uma cirrose do fígado. Lembro-me de um dia ter ido sem nenhum propósito claro ao Museu Britânico e vasculhado os catálogos para ver o que acontecera durante minha longa ausência; as datas em minhas anotações mostram com nitidez que, por um acaso que não posso explicar, aparentemente forcejei nos dois meses seguintes pelas páginas de A teoria do romance (1920), de Georg Lukács, e de Mimesis (1946), de Erich Auerbach. Eu digo que forcejei sobretudo porque isso significa que tive de aprender alemão pela terceira vez. Tanto Lukács quanto Auerbach na realidade contribuíram muito mais para $A$ ascensão do romance do que sugerem as poucas referências no texto.

Na primavera de 1946 me inscrevi para a Commonwealth Fund Fellowship - hoje denominada bolsa Harkness - para dois anos de pesquisa nos Estados Unidos; e, em setembro, dei por mim na Universidade da Califórnia (Ucla). Naquele inverno, num arroubo furioso de energia, escrevi um rascunho de 500 páginas, consegui que as datilografassem e ganhei uma bolsa de pesquisa no St John's College, em Cambridge. Mas, antes de iniciá-la, ainda tinha - se desejasse - um ano e meio para estudar o que quisesse nos Estados Unidos. Em 1947, fiz algumas pesquisas na Ucla em antropologia e sociologia no que era então um democrático e animado grupo de docentes e alunos; mas o resultado mais significativo desse 
desvio pelas ciências sociais foi pôr-me em contato com alguém que certamente seria mais responsável do que qualquer outra pessoa pela configuração intelectual da Ascensão, e pelo longo atraso em sua conclusão, o falecido Theodor Adorno, hoje famoso como líder da Escola de Frankfurt, naquela época situada na área em torno dos Pacific Palisades. Mal havíamos nos conhecido quando ele disse com genuíno interesse que gostaria de ler meu manuscrito. Quando voltei à casa dele poucos dias depois, Adorno me manteve nos degraus da porta explicando sua opinião sobre as dificuldades que envolviam o uso da palavra "gênio"; então, passou a dizer como nunca usava o termo de forma leviana; por fim, bem, a modéstia me proíbe de continuar, mas os elogios que ele empregou me convenceram de que se referia ao manuscrito errado. Mais tarde vim a conhecer Adorno razoavelmente bem, e isso causou três tipos de atraso. Primeiro, não queria ser descoberto, de modo que, por algum tempo, não pude escrever quase nada; segundo, dada a sua visão assustadoramente ampla do que estava à disposição de qualquer pessoa culta, percebi que eu tinha um longo caminho pela frente; e, por fim, passei a entender que o que ele mais apreciava em minha tese eram na realidade os paralelos independentes ou as ampliações de algumas das ideias gerais da Escola de Frankfurt, em especial algumas das ideias veiculadas numa obra que surgiu naquele ano, A dialética do esclarecimento (1947). A discussão, ali, da "astúcia da razão tecnocrática" tem alguma semelhança com partes de A ascensão do romance: o que eu havia dito sobre Robinson Crusoe; o que sugeri sobre as potencialidades da exploração de massa contida na identificação mais estreita entre a obra literária e o leitor, que se tornou possível graças à imprensa e àquilo que já chamei de "realismo formal"; e, de modo mais abrangente, o que disse sobre as ligações maiores entre cidade e privatização burguesa, contidos no capítulo que trata da imprensa e da experiência privada.

Adorno foi uma pessoa muitíssimo fértil e generosa; havia uma pureza, quase uma inocência infantil em seu entusiasmo pela vida do espírito; ele me pôs em contato com toda a tradição do pensamento alemão na história, na literatura, na sociologia e na psicologia; e o fez do único modo que isso poderia ter sido feito para mim, porque eu nunca teria acreditado que as pessoas de fato pensavam assim até que vi Adorno em ação, dia após dia.

O efeito mais imediato que ele exerceu sobre A ascensão foi obrigar-me a pôr de lado o manuscrito até sentir que estava pronto para novos voos; nesse meio-tempo comecei a escrever um livro bem diferente, que tratava, no contexto teórico mais amplo possível, de literatura, leitura, memória e tecnologia. Se tivesse concluído esse livro - então chamado de "Printed Man" -, eu poderia ter-me tornado o São João Batista de Marshall McLuhan. Tudo o que apareceu dessa versão foi um longo artigo escrito em colaboração com um amigo antropólogo, Jack Goody, intitulado "The Consequences of Literacy".

\footnotetext{
${ }^{5}$ Jack Goody; Ian Watt, "The Consequences of Literacy", Comparative Studies in Society and History, v. 5, p. 304-45, 1963. Reimpresso em Literacy in Traditional Societies, ed. Jack Goody, Cambridge, Cambridge University Press, 1968, p. 27-68.
} 
No segundo ano da bolsa, 1947-1948, segui para Harvard; e ali, entre outras coisas, continuei exposto ao pensamento alemão. Assisti ao seminário de Talcott Parson sobre teoria social, e aprendi alguma coisa sobre Max Weber. Isso se refletiu, creio eu, não apenas no tratamento das forças econômicas e institucionais na Ascensão do romance, mas também em algumas de suas ideias norteadoras mais abstratas - a noção, por exemplo, do desencanto do mundo sob o impulso do racionalismo científico e econômico (Entzauberung der Welt), associado ao Iluminismo. Também aprendi com Parson - embora resistindo o tempo todo - a ver a sociedade em termos estruturais e funcionais; ou seja, a ver a sociedade não como algo incapaz de ser o que eu gostaria que fosse, como algo que foi no passado ou que poderá ser no futuro, mas sim como algo que existe e que se manifesta através de um equilíbrio de forças institucionais e culturais dominadas pela tensão e em constante mudança. Esse tipo de pensamento me fez enxergar a dubiedade de muitos pressupostos incontestes que mais ou menos colhi de todo tipo de fonte - Platão, Matthew Arnold, os Leavis, o marxismo e a Escola de Frankfurt, por exemplo. Eu, é claro, não sufoquei todos os meus impulsos pessoais de crítica ou repulsa social, mas me tornei muito mais consciente deles; um resultado, creio, foi dar um grau muito maior de objetividade aos aspectos sociológicos e históricos de A ascensão do romance.

Um impulso correlato - na direção de uma penetração mais direta e imediata dos autores que vinha estudando e de uma compreensão mais ampla das atividades de minha própria consciência durante o processo - foi fortalecido por outro encontro casual. Aron Gurwitsch, então estudando matemática em uma pequena escola local, embora já fosse editor do Journal of Philosophy and Phenomenological Research, apresentou-me ao pensamento de Brentano, Husserl e Merleau-Ponty. O que ficou de modo mais nítido foi a estimulante vitalidade de seu desprezo sardônico pela maioria dos assuntos que surgiam durante a conversa; mas também aprendi algumas maneiras de superar o positivismo em meu tratamento da intenção, da expectativa cotidiana e da projeção imaginativa.

\section{Síntese: 1950-1956}

De volta a Cambridge, na Inglaterra, em 1948, a dificuldade de terminar o livro sobre o letramento, somada à necessidade claramente relacionada de ganhar a vida, enfim me fez regressar ao amarfanhado manuscrito sobre o romance do século XVIII. Foi primeiramente usado como fonte de artigos isolados. O primeiro foi "A designação dos personagens em Defoe, Richardson e Fielding" (1949); os vestígios fenomenológicos talvez expliquem por que só foram republicados na Alemanha. O segundo artigo, "Robinson Crusoe as a Myth" (1951), teve tamanha influência de Adorno, e mais diretamente de Weber e de Stamm, que um crítico americano, talvez perturbado com meu afastamento da então assentada tendência de ver o século XVIII inteiramente nos termos do século XVIII, parece ter presumido que eu era alemão. (Os outros dois, um sobre uma atribuição equivocada a Defoe e o outro sobre o ponto de vista de Defoe e Richardson sobre Homero, revelam de forma mais ou menos direta as diversas influências do positivismo e de Georg Lukács.) 
Quando comecei a trabalhar no manuscrito como um todo, me dei conta de que minha nova compreensão do assunto, e até mesmo meu senso ora iniciado do que poderia ser uma completa compreensão, estava me levando para uma empresa muito mais ambiciosa do que aquela que eu em princípio concebera, uma empresa ainda mais impossivelmente demorada.

Como poderia combinar todas as informações que havia reunido com as ideias que as dotavam, eu agora imaginava, de um significado mais amplo? A resolução que dei ao problema foi draconiana, tanto em termos de substância quanto de forma. Quanto à substância, expressei minhas ideias mais largas, filosóficas e históricas, apenas quando elas pareciam diretamente relacionadas com o tema à disposição, e geralmente apenas quando havia evidência suficiente para ilustrá-las a partir das fontes primárias. Por outro lado, reduzi drasticamente as informações empíricas, e deixei poucas que não iluminassem as perspectivas intelectuais mais dilatadas. Quanto à minha estratégia retórica, foi fundamentalmente de estilo, no sentido de que queria evitar tudo o que pudesse ser indigesto, no tocante tanto a uma excessiva documentação empírica quanto a desmedidas abstrações filosóficas.

De certo modo, meu método geral inverteu o de Adorno. No prefácio à edição inglesa de Prismas, o filósofo rende homenagem ao que "aprendeu com as normas anglo-saxãs de pensamento e apresentação". Ocorre, porém, que isso é puramente "como um controle, por receio de rejeitar o senso comum sem tê-lo antes dominado"; e então Adorno paradoxalmente conclui que "é somente pelo uso de suas próprias categorias que se pode transcender o senso comum". ${ }^{6}$ De algum modo, ele me ajudou a superar o senso comum; mas meu principal objetivo pode ser expresso nos termos do paradoxo oposto: o de transcender o que eu havia aprendido com as modalidades idealistas do pensamento alemão traduzindo-o em categorias empíricas e linguagem de senso comum.

Essa síntese final foi amplamente intuitiva; até onde me acode qualquer influência específica sobre minha estratégia de composição, essa deve ser eco da lembrança daquilo que I. A. Richards me disse com sua sutileza caracteristicamente cordial depois de ter lido meu manuscrito: "Se eu fosse você, Ian, me manteria afastado das grandes empresas transportadoras".

Em retrospecto, portanto, espero enxergar sob a modesta superfície de A ascensão do romance as perturbadas subcorrentes de um conjunto bastante representativo das principais tendências intelectuais de seu período de gestação - 1938 a 1956. É essencialmente uma síntese parcial, e em muitos aspectos amadora, de duas grandes, mas bastante distintas tradições de pensamento: em primeiro lugar, os elementos empíricos, históricos e morais de minha formação em Cambridge; em segundo, os muitos outros elementos teóricos da tradição europeia - o formalismo e a fenomenologia, em menor escala; e o marxismo, freudismo e a Escola de Frankfurt, em uma escala de certo modo mais ampla.

${ }^{6}$ Theodor Adorno, Prisms, trans. Samuel and Shierry Weber, London, Spearman, 1967, p. 7 [ed. bras. Adorno, T. W. Prismas. Crítica cultural e sociedade, São Paulo, Ática, 2001]. 
Eu demoraria muito tempo para ilustrar essa síntese; e ela também me obrigaria a reler o livro. Mas ao olhar para o primeiro parágrafo já noto um certo indício prefigurativo dessa união entre o empírico e o não empírico; o parágrafo vai de uma pergunta com como, para uma pergunta com por quê: de "como a (prosa de ficção do século XVIII) se difere (daquela) do passado" até "há algum motivo para essas diferenças terem aparecido em determinada época e em determinado local?" (p. 11).

Que A ascensão do romance tenha tirado proveito dessas várias presenças filosóficas, embora elas tenham sido no máximo rapidamente mencionadas em notas de rodapé ou no prefácio, parece-me bastante evidente; entre outras razões, talvez seja essa a que provavelmente responde pela crescente atenção que o livro recebeu nos últimos anos; suponho que a base de sua atualidade quase póstuma em parte deve residir no fato de que sua substância e que sua ênfase estiveram bem mais em contato com um vasto espectro da ideologia moderna do que parecia, à primeira vista. O esquema de sua recepção, creio, é a prova disso.

\section{Traduções e reações na Europa}

As duas primeiras traduções vieram à luz em 1974: na Alemanha, como Der Bürgerliche Roman, e na Polônia, como Narodziny Powiesci (O nascimento do romance). Esses dois títulos não são, creio, casos de tradução equivocada. A mera ausência - não só no alemão, mas também no polonês e em várias outras línguas - da distinção que se faz em inglês entre novel e romance torna impossível a tradução literal de A ascensão do romance. ${ }^{7}$ Chamá-lo, ao contrário, de "O romance burguês" é chamar primordialmente a atenção ao aspecto histórico-social do livro de uma perspectiva marxista; e essa mesma ênfase ocorre na tradução italiana - Le origini del romanzo borghese (1976). Essa versão inclui um longo ensaio do tradutor, Luigi del Grosso Destreri, "Cultura burguesa e cultura popular". Destreri lamenta que os "assim chamados sociólogos da literatura" não "refletiram com seriedade" sobre "il Watt", em parte por causa das "posições lógico-positivistas" do livro; ele então propõe um "segundo nascimento" para a obra aproveitando a ocasião para uma "discussão mais ampla sobre as condições de produção dos modelos culturais".

O ensaio é interessante, mas só tenho tempo para discutir uma questão, pequena em si mesma, mas que ilustra tanto as vantagens quanto as desvantagens do meu método de composição empírica. Destreri me censura por ter "descrito, mas deixado de nomear" o fenômeno da alienação e anomia, mas me elogia por ter-me "inadvertidamente inserido na tradição crítica de Lukács e Lucien Goldmann". Na verdade, eu não tinha, nos anos 1950, ouvido falar de Goldmann, embora ele por sua vez refletisse as ideias de algumas das figuras de Frankfurt cujas obras eu conhecia, como Franz Borkenau, Walter Benjamin e Bernard Groethuysen; quanto

\footnotetext{
${ }^{7}$ Watt refere-se à distinção entre romance, relato ou novela de caráter fantástico ou romântico, e novel, o romance propriamente dito. Tanto o termo alemão Roman quanto o polonês powiesc traduzir-se-iam com mais propriedade como romance (novel). (N. do T.)
} 
a Lukács, eu havia lido e, até certo ponto aceitado, algumas de suas posições hegelianas e marxistas. Mas eu dificilmente poderia ter explicitado quer minha dívida, quer minha discordância com Lukács ou com a Escola de Frankfurt na Ascensão do romance sem introduzir grandes questões conceituais que teriam desviado minha atenção, e a dos meus leitores, das proximidades concretas de meu assunto. Foi por motivos semelhantes que até mesmo evitei o uso da palavra "burguês" (exceto em citações). Assim, da mesma forma que o termo "alienação", usado por Hegel, Marx ou pensadores posteriores, implica um estado anterior de harmonia espiritual, econômica e social cuja verdadeira existência histórica eu questiono, também o sentido marxista de "burguesia" implica uma vasta teoria histórica e política. Eu empreguei vários aspectos concretos dessa teoria, mas evitei o termo em si, porque ele invocava ideias metafísicas que eu rejeitava. Por outro lado, se não mencionei minha discordância, foi por não ter razões para acreditar que meus argumentos teriam algum interesse particular para outras pessoas, já que fazia tempo que eles deixaram de ser interessantes para mim.

Esse repúdio ao interesse ideológico teve, para mim, a ampla vantagem de afinar o foco do assunto em pauta; mas eu tenho razão para acreditar que, no caso, a recusa não diminuiu a pertinência do que eu tinha para dizer. Eu soube, por ensaios, conversas e cartas, que os leitores de A ascensão do romance na Polônia, na Hungria e na Romênia, por exemplo, acharam na obra uma relevância hodierna, até mesmo um menor interesse polêmico, que certamente não foi intencional; e essa pertinência está diretamente relacionada às mesmas questões que me fizeram evitar os termos "burguês", "alienação" e "anomia". A questão, dizendo simplesmente, é se os valores burgueses e toda gama de descontentamentos da sociedade, representados pelos conceitos de "alienação" e "anomia" são, como presumem Marx e Durkheim, o resultado temporário de uma fase específica no desenvolvimento da produção capitalista. Para os escritores nos países socialistas, a questão - diametralmente oposta aos pressupostos do ali predominante "realismo socialista" - é se as manifestações sociais, espirituais e literárias do individualismo alienado podem não ter de fato muito pouco a ver com quem detém os meios de produção. Quem sabe não seja, muito mais, parte do processo evolucionário de mudança das pequenas sociedades tribais para aquelas do moderno estilo de vida urbano, de larga escala industrial. Quem sabe todo o ciclo do que costumava ser intitulado "individualismo burguês" - e o tipo de romance a ele associado - não seja um estágio histórico necessário no desenvolvimento literário e intelectual de todas as sociedades industriais desenvolvidas?

\section{Alguns aspectos do termo "realismo"}

Chego enfim um pouco mais perto do tópico sugerido pelo meu título. Se eu tivesse de usar um rótulo crítico, não tenho nenhuma objeção especial ao de "realista sociológico", que me foi recentemente imputado por Mark Spilka, ${ }^{8}$ embora

${ }^{8}$ Spilka, p. viii. 
minha reação básica seja de um bocejo acompanhado por um apelo de nolo contendere. Minha impaciência tem menos a ver com o "pressuposto geral de que o "realismo" é uma postura metafísica pedestre e canhestra do que com o fato de que no uso crítico o termo implica controvérsias que, após cerca de um século, claramente se deterioraram. Mas creio que pode ser produtivo tentar examinar dois aspectos gerais do problema a que se ligam as questões do realismo. Antes, porém, algumas poucas palavras sobre o sentido subjacente aos termos que empreguei, "realismo de apresentação" e "realismo de avaliação", com respeito às ideias filosóficas que forneceram a segunda, e antitética, etapa da gestação de $A$ ascensão do romance.

\section{Realismo de apresentação}

Em A ascensão do romance, o "realismo de apresentação" ou "realismo formal" foi uma maneira de estabelecer uma distinção entre o aspecto puramente técnico da representação narrativa do mundo real e a verdade ou a substância da obra literária. Percebi que três obras recentes fazem uma distinção similar. Assim, Ernst Fischer, em The Necessity of Art (1967), fala de um aspecto do realismo como "um método específico" dos romances e peças oitocentistas. Damian Grant usa a categoria "realismo consciente"; e em seu arguto estudo, On Realism (1973), J. Peter Stern descreve o realismo na literatura como "um meio de retratar, descrevendo a situação de uma maneira fiel, acurada, 'semelhante à vida", e acredita que a qualidade especial da "ficção do século XIX" contém "mais elementos realistas do que na literatura anterior". ${ }^{9}$ E, A ascensão do romance, estive ocupado com a pré-história desse processo; e se fiz algum progresso em relação a considerações anteriores foi em associar o realismo formal ou de apresentação a dois tipos diversos de causas, tipos que, por sua própria natureza, expuseram-nas de modo bastante desigual às vicissitudes históricas.

Havia, em primeiro lugar, as causas que atribuí a transformações filosóficas, sociais, econômicas e educacionais que afetaram tanto os autores como o público leitor, transformações que conduziram a uma ênfase sobre o indivíduo, sobre a particularidade do tempo e do espaço, sobre o universo material e a vida cotidiana: todos esses, entre outros fatores históricos, criaram uma versão substancialmente nova da antiga preocupação da literatura com a verossimilhança; mas, como algumas dessas mudanças foram essencialmente sociais, supus que não apenas o conteúdo específico da ficção setecentista, mas ainda alguns aspectos de seu notável idioma particular provavelmente não sobreviveriam ao período. Mas existiam outras espécies de causas muito menos sujeitas à contingência histórica: em primeiro lugar, havia a autoridade do pseudorrealismo da imprensa, que atribuí ao meio tecnológico; e, em segundo, a correspondente instauração do silêncio e da

\footnotetext{
${ }^{9}$ Ernst Fischer, The Necessity of Art: A Marxist Approach, trans. Anna Bostock, Harmondsworth, Penguin, c. 1963, p. 106; Damian Grant, Realism, London, Methuen, 1970; J. Peter Stern, On Realism, London and Boston, Routledge and Kegan Paul, 1973, p. 40, 41.
} 
leitura privada como modo característico de desempenho romanesco. Esses fatores, supus, derivavam da própria modalidade da produção literária, e haviam assim contribuído para mudanças qualitativas permanentes no idioma expressivo da ficção; o efeito objetivo e, contudo, privado da página impressa possibilitou uma espécie de apresentação realística capaz de durar muito mais tempo.

Meu tratamento do realismo formal, portanto, deveria mostrar-se bastante independente do tipo de consideração envolvida com o realismo como nome de uma determinada escola literária; interessava-me menos ainda o realismo como uma doutrina crítica consciente que supostamente professa que a ficção é ou deveria ser uma reprodução fotográfica verbal da realidade, ou uma imitação direta, não mediada, da vida.

A dificuldade semântica relacionada com o realismo parece ser aqui insuperável, em grande medida porque somos todos - e de forma idêntica - especialistas em "realidade"; e, portanto, sentimo-nos autorizados a usar a terminologia do modo que nos apraz. Como resultado, o debate atual, ou melhor, a ausência de debate, sobre o realismo é, em essência, um tipo de luta de boxe com um oponente imaginário, onde os golpes nunca acertam porque o ringue é amplo demais: com efeito, não há cordas. A esmagadora vitória de facto dos antirrealistas na atual arena crítica depende de dois pressupostos básicos: o de que, como houve uma escola literária francesa em meados do século XIX que usava o termo "réalisme", e como o rótulo se ampliou a ponto de abarcar todo um percurso ficcional desde Balzac e Stendhal até Zola e o bom Dean Howells, o realismo, em todos os seus aspectos, deve por conseguinte ser algo "não moderno" e, portanto, liquidado. Quando o crítico antirrealista vai além desse uso implicitamente histórico do termo, o modelo analítico do realismo permanece sendo o da ingênua reprodução fotográfica da realidade. Albert Guerard, por exemplo, em seu excelente livro The Triumph of the Novel (1977), caracteriza Dickens, Dostoiévsky e Faulkner como "não realistas", porque evidentemente não fingiam ser espelhos ou câmaras fotográficas do cotidiano. Entretanto, independentemente do que Stendhal ou, com efeito, Hamlet e outros possam ocasionalmente ter dito, nenhum escritor jamais pensou seriamente em ser somente um espelho; mas o pressuposto de que o realismo somente pode significar a imitação fotográfica do mundo exterior fornece aos críticos um alvo fácil demais para que eles deixem passar. Em todo caso, meu conceito de realismo formal ou de apresentação não pretendeu implicar nenhuma restrição de uso; sua maneira específica, detalhada, de representar o mundo interior ou exterior pode ser aplicada com a idêntica facilidade ao melodrama, ao divertimento, à involução ou ao que Guerard chama de "distorção iluminadora". As possibilidades técnicas do realismo de apresentação são, em si, bastante neutras; podem servir a vários propósitos: de fato, nos três romancistas de que trata Guerard percebem-se com clareza muitas técnicas de ficção de cuja pré-história e base analítica eu me ocupei em A ascensão do romance. Todos os três, para dar um exemplo óbvio, conjugam uma preocupação quase obsessiva com os objetos e aspectos físicos do ambiente a um cuidado idêntico em mostrar que a vida interior do indivíduo é em ampla medida separada e autônoma - um efeito atingido de modo diverso por 
aquilo que eu disse sobre Robinson Crusoé e Pamela, mas que dificilmente poderia ser alcançado sem que a ilusão da página impressa fizesse que o mundo interior e exterior parecessem igualmente "reais".

\section{Realismo de avaliação}

Em A ascensão do romance procurei estabelecer outra categoria de naipe bem diferente, o realismo de avaliação, que deveria levar em conta todas as diversas maneiras pelas quais o romance, como todos os gêneros literários, contém elementos estruturantes diversos daqueles de propósito representacional. Autores que posteriormente trataram do realismo usaram termos semelhantes. Ernst Fischer fala de "realismo de atitude" (Realismus der Haltung), Damian Grant refere-se ao realismo "consciente" ou "consciencioso", e Peter Stern distingue realismo "descritivo" de realismo "apreciativo". ${ }^{10}$ Todas as três distinções levam em consideração o fato de que as predisposições intelectuais, emocionais e estéticas do autor estão inevitavelmente presentes, em vários níveis de consciência, em toda prosa de ficção, assim como em outros gêneros literários; e essas predisposições podem variar de simples preferências relativas à hierarquia de atenção do escritor (Ann Radcliffe usa lariços em vez de magnólias, digamos) a conjuntos muito mais amplos de princípios e valores organizadores. Assim, a admiração de Lukács pelos realistas - de Scott e Balzac a Tolstoi - e sua rejeição aos naturalistas baseiam-se em seus próprios valores filosóficos, políticos e estéticos, que o fizeram rejeitar qualquer atitude mecânica, conformista ou passiva com relação ao mundo material e social.

O conceito de realismo de avaliação pretendeu, em níveis mais altos de abstração, incluir não apenas distinções como essas, mas outras, desde a insistência fenomenológica sobre a atividade estruturante da consciência (a "consciência estruturante" de Jean Starobinski) até as questões supremas sobre o conhecimento e a verdade de uma obra literária.

Sinto-me, assim, devidamente envergonhado por insultar a sofisticação dos senhores com o uso de termos tão deteriorados como conhecimento e verdade; mas eles claramente fazem parte de minha manifesta preocupação em A ascensão do romance; e eu gostaria de terminar apreciando o que julgo ser um problema muito mais sério do que as atuais objeções ao realismo na ficção: a questão sobre como e por quê os atuais rumos dominantes na crítica literária tendem a negar ou negligenciar o verdadeiro status da literatura e a considerar que o realismo de avaliação crítica só interessa aos pedagogos de pés chatos.

\section{Filosofia, realismo e crítica literária: realismo e estruturalismo}

Creio que não é difícil entender por que o termo "realismo" não entusiasma os círculos filosóficos. Salvo os diversos usos históricos especializados de que

\footnotetext{
${ }^{10}$ Fischer, op. cit., p.116-17; Grant, cap. 2 e 3; Stern, cap. 8.
} 
não precisamos nos ocupar aqui, ele denota, muito simplesmente, a aceitação de três noções gerais: o mundo e as pessoas ao nosso redor são reais, a linguagem permite-nos comunicar uns com os outros sobre eles e a verdade sobre eles se verifica através do assentimento dos outros observadores. Em relação a nossos procedimentos práticos, até onde sabemos que estamos no mundo real, essas noções não despertam nenhuma dificuldade especial. Não imagino que o semiótico mais arrojado não seja obrigado a concluir que precisa comer para viver: não acredito que ele vá ao banco trêmulo e apavorado, com receio de que o significado das palavras escritas em seu cheque seja posto à prova pelo caixa; nem mesmo que o número de dólares em questão algum dia tenha provocado paroxismos de hesitação hermenêutica. Também creio razoável supor que a filosofia, como instituição social especializada, não poderia ter começado a existir caso tivesse meramente sustentado os pressupostos corriqueiros sobre a realidade do mundo exterior ou a possibilidade de conversar sensatamente sobre ela com os nossos amigos; o primeiro cheque emitido a um filósofo certamente deve ter sido pago a um sofista que provou que nossas necessidades materiais são irreais, que a linguagem que usamos de fato não tem nenhum significado ou, se tiver, esse é decididamente problemático.

Assim, todo o empreendimento da filosofia ocidental desde os pré-socráticos dependeu em grande parte da negação paradoxal daquilo que todos sabemos ser, em um modo simples, verdadeiro: e essa visão essencialmente antirrealista das coisas ganhou sua decisiva formulação estética na era moderna com a Crítica do juízo (1790), de Kant, onde ele estabeleceu a oposição entre realismo e idealismo, que hoje vigora no pensamento crítico.

No fim do século XIX, quando o simbolismo e o impressionismo sucederam o realismo e o naturalismo, a posição antirrealista também passou a dominar a literatura. A perspectiva crítica geral mudou em conformidade, por fim alcançando a academia em uma época em que a filosofia estava sendo substituída pela literatura como a rainha das ciências. Agora, por uma familiar inversão dialética, o que passa por filosofia em ampla medida dominou a área dos estudos literários. Nas últimas décadas, esse processo foi materialmente amparado pelo prestígio, autoconfiança e recompensas financeiras muito maiores das ciências naturais e, até certo ponto, das ciências sociais. Essa rivalidade levou a uma enorme compulsão para encontrar um método autônomo e semicientífico que sirva ao estudo da literatura; e hoje em geral se pressupõe que algum tipo de técnica semifilosófica é pré-requisito indispensável para abordar ou discutir qualquer obra literária.

A forma mais extrema e influente dessa técnica analítica é, por certo, o estruturalismo. Ele se ocupa das verdades eternas em um nível muito mais profundo do que o das particularidades das obras literárias individuais, e rejeita como uma relíquia desacreditada (ou, de qualquer modo, bastante enfadonha) do passado a noção de que as funções referenciais da linguagem e, portanto, o status representacional da literatura ainda mereçam a atenção da mente sofisticada. Como disse Roland Barthes, no O grau zero da escritura (1953), com cativante determinação: 
Le réalisme, ici, ce ne peut donc être la copie des choses, mais la connaissance du langage; l'œuvre la plus "réaliste " ne sera pas celle qui "peint " la réalité, mais qui, se servant du monde comme contenu (ce contenu lui-même est d'ailleurs étranger à sa structure, c'est-à-dire à son être), explorera le plus profondément possible la réalité irréelle du langage. ${ }^{11}$

Barthes está tratando da mudança da ficção tradicional para a engenharia verbal, quase filosófica, do nouveau roman; mas ele de fato parte do princípio usual de que o realismo deve ser identificado com a mera cópia das coisas. Ele assim me fornece uma desculpa para aquela breve excursão a Paris que eu prometi aos senhores: uma explicação sócio-histórica que algum historiador impaciente poderia ter escrito se tivesse começado a reunir anotações para um livro sobre a "ascensão do estruturalismo".

Após a Primeira e a Segunda Guerras Mundiais ocorreu um grande e contínuo êxodo de intelectuais dos países derrotados - Rússia, Hungria, Romênia, Bulgária, Áustria, Checoslováquia e Alemanha. Esses intelectuais levaram consigo hábitos de pensamento que se baseavam em sua experiência em instituições acadêmicas, que lhe havia conferido considerável prestígio social, mas nenhuma importância na vida política e nacional como um todo. As circunstâncias do exílio consolidaram a necessidade dos mesmos hábitos de pensamento. O primeiro pré-requisito era o de criar um sistema intelectual que lhes fornecesse um indiscutível status de sábio; ao mesmo tempo, esse sistema tinha de basear-se numa abordagem da verdade que desdenhava ou transcendia todas as diferenças nacionais, históricas e psicológicas - e não atentava para o destino que recaíra sobre seus próprios países ou para as várias idiossincrasias e hostilidades que encontravam em seus países de adoção.

Depois de 1945, Paris lhes oferecia de longe o ambiente institucional e intelectual mais favorável de todos; um ambiente favorável em certa medida para os pensadores franceses também. A humilhação de Vichy em 1940 fez que a reafirmação da grandeza nacional se tornasse imperativa; ao mesmo tempo, o status bastante privilegiado da alta burguesia francesa sobrevivera, quase intacto. Com efeito, no que diz respeito às elites acadêmicas, esse status logo se ampliou. Para dar um exemplo, a urgência da reconstrução levou o governo a criar uma forte política nacional de pesquisa (Centre Nationale de Recherche Scientifique); alguns humanistas, aliás, como Todorov, se beneficiaram disso. Ao mesmo tempo, a rígida política centralizadora da tradição francesa manteve-se irredutível; assim, um grupo relativamente pequeno de gente que se destacava nos competitivos exames das Grandes Écoles ocupou os principais postos. Até mesmo o efeito da nova ênfase nos negócios e na tecnologia não foi inteiramente desfavorável porque, embora tivesse liquidado a antiga aliança entre a École Normale e o poder político, o sistema permitiu que seus beneficiários combinassem cargos no governo com

${ }^{11}$ Citado por Stern, p. 165. Em sua palestra Ian Watt traduziu essa passagem da seguinte forma: "O realismo não pode ser a cópia das coisas, mas o conhecimento da linguagem; a obra mais 'realista' não será a que 'pinta' a realidade, mas que, usando o mundo como conteúdo (um conteúdo, aliás, estranho à estrutura da obra, ou seja, à sua essência), conduz a exploração mais profunda possível sobre a realidade irreal da linguagem". (N. do E.) 
impecáveis credenciais de esquerda; foi o caso de Althusser no ministério da Educação, por exemplo.

Os principais estruturalistas operam no alto da hierarquia acadêmica parisiense - Barthes e Foucault no Collège de France, Todorov e Genette na École des Études Pratiques. Estão quase inteiramente livres de quaisquer amarras ou responsabilidades educativas impositivas. Não têm de dar aulas - ou quase nenhuma -, uma dúzia de palestras sobre tópicos escolhidos por ano é a norma; não têm obrigação de preparar os alunos para os exames ou de ater-se a um programa - isso fica a cargo da própria universidade, quando fica; para as palestras não se pressupõe que os alunos tenham lido algum dos textos em discussão - na realidade, é bastante difícil descobrir de antemão quais serão esses textos. A essência do sistema é promover com brilhantismo a verbalização idiossincrática, livre de qualquer amarra controladora que não seja expressão imediata do ego cartesiano enquanto pensa: é tudo cogito, nenhum cogitamus. As únicas verdadeiras restrições externas são as que partilham com a indústria da alta costura parisiense. Aguardam-se novos projetos estruturais todos os invernos com a mesma regularidade com que a altura das saias sobe ou desce nos salões da moda ou com que se produzem novos modelos de automóveis em Detroit. Isso explica os livros anuais que passamos a esperar dos principais autores estruturalistas, livros que estão fadados a expressar opiniões bem diferentes dos últimos publicados, porque a obsolescência passou a fazer parte do jogo, e você só consegue participar dos programas noturnos de entrevista da televisão nacional francesa se tiver produzido algo novo.

\section{Crítica filosófica e literatura}

Minha supersimplificação satírica não pretende, é claro, ser toda a verdade, nem mesmo acerca de minhas próprias opiniões; eu aprendi com alguns estruturalistas, mantenho relações amistosas com alguns deles e até mesmo fui traduzido para um número da Poétique. Mas estou convencido de que o estruturalismo exacerba o que considero uma visão equivocada da natureza da crítica literária, e estou certo de que isso tem efeitos desastrosos no que diz respeito ao ensino da literatura. O erro mais evidente está no pressuposto monstruoso de que a crítica literária, ou a filosofia da obra literária é inerentemente superior à própria literatura, ou, se não for o caso, é ao menos um pré-requisito indispensável para compreendê-la. A noção básica do papel superior do crítico é, suponho, em essência uma tentativa de resguardar numa nova roupagem as antigas reivindicações da filosofia. Mas não precisamos de Blake, de Kant ou de Matthew Arnold para nos dizer que aquilo que a literatura oferece de mais característico é a materialidade do caso específico imaginado, de modo que há uma diferença essencial entre discurso literário e discurso filosófico. Quanto mais o crítico se aproximar da generalidade das declarações filosóficas, mais ele inevitavelmente se distancia da literatura que está analisando. Parece-me igualmente equivocada a ideia de que precisamos de uma ontologia teórica da obra literária, ou da linguagem, para entendermos a literatura. Ela supõe que a literatura, como as formas platônicas, não é visível ao olho nu, e que precisamos de um equipamento especial para observá-la. Mas, 
ao contrário dos mistérios da metafísica, ou mesmo da fé na ciência, a obra literária está realmente ali, e só exige nossa própria experiência de vida e de linguagem para que possamos decifrar o seu sentido. Pois, para ler a literatura, como afirma Auerbach, não precisamos de nada mais do que "confiança empírica em nossa faculdade espontânea de entender os outros com base em nossa própria experiência". ${ }^{12}$

Na prática, a crítica filosófica impede a aproximação com a literatura de pelo menos três maneiras. Antes de mais nada, se o leitor comum convencer-se de que necessita de um equipamento analítico especial, poderá descobrir que é incapaz de dominá-lo, ou, se for, que a técnica não o ajuda, com efeito, a entender Rei Lear ou Alice no país das maravilhas. Em seguida, se o leitor aceitar a reivindicação do crítico por um papel transcendental, poderá ser humilhado ao descobrir que suas próprias explorações são muito menos excitantes: um vidente é, por definição, alguém capaz de ver o que ninguém mais consegue; o crítico-vidente faz o mero mortal sublunar sentir-se cego diante da literatura; e assim ele desiste de maiores esforços em seu desespero de algum dia conseguir capturar sequer um vislumbre do lado obscuro da Lua, como os profetas parecem fazer o tempo todo. Eles pertencem, basicamente, ao maior lobby dos Estados Unidos - o lobby da ansiedade - que vai dos fabricantes de armamentos bélicos e a Madison Avenue até Ralph Nader e alguns ambientalistas.

Por fim, a crítica filosófica tende a ver a literatura em termos exclusivamente cognitivos. Por causa disso, somos obrigados a esquecer que a condição da grande verdade da literatura em relação à vida é não ser exclusivamente cognitiva; que ela cobre um vasto raio de ações e sentimentos humanos, de coisas lembradas e imaginadas; e que tratá-la como algo cognitivo tanto no que diz respeito ao assunto quanto ao significado implica não apenas representá-la de modo anômalo, como ainda impedi-la de cumprir a faculdade literária de ampliar afinidades imaginativas.

Essa ampliação é certamente um dos principais motivos para a literatura ocupar o lugar que ocupa no currículo escolar: como diz Coleridge: "a imaginação é a característica distintiva do homem como ser avançado". ${ }^{13}$

A oposição entre teoria e a experiência imaginativa direta é particularmente óbvia no caso do estruturalismo. Os enfants terribles de Paris, como os de outros lugares, são em certo aspecto inumanos: não são nem infantes nem adultos; e seu brilhante comando do aparato verbal de um adulto ao mesmo tempo mascara a ausência de outros tipos de entendimento e obsta que esse apareça na sua escrita. Suas falas versam sobre profundas estruturas universais; mas essas estruturas são produzidas por exclusões extravagantes que desafiam a experiência humana. Em todo caso é decerto pouco produtivo, em uma época em que a leitura está em baixa e se faz com menor naturalidade, alardear a mensagem "Cuidado com os

${ }^{12}$ Erich Auerbach, Literary Language and Its Public in Late Latin Antiquity and in the Middle Ages, London, Routledge and Kegan Paul, 1965, p. 7.

${ }^{13}$ Veja Lecture 11, Lectures 1808-1819 On Literature, ed. R.A. Foakes, Princeton, Princeton University Press; London, Routledge and Kegan Paul, 1987, 2v. v. 2, p. 193, em The Collected Works of Samuel Taylor Coleridge. (N. do E.) 
funestos binários, os dragões da profundeza", em vez de "Entrem, a água está ótima"; e não ajuda mapear o mundo inteiro da literatura com marcadores que acabam por anunciar o advento dos mesmos monstros binários, especialmente quando os nomes deles mudam de ano a ano.

Uma objeção final. O efeito educacional atualmente promovido pela corrente da crítica filosófica em última instância prejudica mais do que ajuda a promoção de modos filosóficos de pensamento. Pois, bem à parte da assombrosa inadequação lógica de escritores como Lacan, as obras dos estruturalistas em geral são lidas de segunda ou terceira mão; uma grande massa de livros escolares oferece kits de faça-você-mesmo que prometem ao usuário transformar-se magicamente naquilo que ele mais deseja ser - um filósofo que não faz filosofia.

Esse macabro fenômeno acadêmico dos dias de hoje foi bem descrito pelo contista Leonard Michaels, numa versão burlesca de Swift:

Ao fazer o inventário, o gerente de uma nova livraria de Berkeley descobriu que foram roubados milhares de dólares em livros. A maioria era de filosofia. Ele decidiu que as pessoas que estudam filosofia sempre conseguem imaginar razões que lhes permitem roubar... Mas mesmo se o gerente estiver correto em seu raciocínio de que os filósofos conseguem racionalizar suas idiossincrasias criminais, que dizer dos outros livros furtados? Estes eram sobretudo de crítica literária e, como o gerente observa com grande amargura, a crítica literária é a filosofia da literatura.

Por acaso, o livro de crítica literária roubado com maior frequência foi Poética Estruturalista, de Jonathan Culler (treze dólares). Essa obra examina todas as novas teorias estruturalistas e semióticas vindas principalmente da França. As teorias estão deliciosamente na moda, malgrado apenas estabeleçam uma relação sistemática entre textos literários e as diferentes leituras dos críticos. Nenhuma dessas teorias, de acordo com Culler, é muito lógica.

Você poderia imaginar que não haveria muita gente querendo ler acerca de teorias ilógicas, mas Culler escreve de forma bastante inteligente e as teorias são interessantes. Assim, teorias interessantes explicadas por um crítico inteligente fizeram com que o livro se tornasse irresistível para os ladrões. O detalhe realmente significativo, porém, é que o livro de Culler é o que se pode chamar de filosofia da filosofia da literatura. O livro de Culler é, portanto, o livro mais filosófico da loja! Ele aguça os instintos mais furtivos de aquisição.

Só Deus sabe quantas cópias de Poética Estruturalista foram roubados. (O gerente dessa nova loja perdeu dezessete exemplares a cada vinte, e agora mantém o livro de Culler debaixo do balcão.) Mas quantas cópias foram roubadas nas cidades universitárias do mundo todo? Quantos filósofos acomodam-se todas as noites com um Culler quentinho? Quantos não se extasiam página após página através de deliciosas análises de teorias críticas que não falam de nada, salvo outras teorias críticas! (Seria demais dizer que teorias que tratam de teorias são algo semelhante a um inchaço da cabeça?)

Há uma história sobre um ladrão de livros em Cambridge que foi pego roubando um Culler. A polícia conseguiu um mandado de busca, vasculhou o apartamento e encontrou sessenta e três Cullers em seu baú de enxoval. Todos haviam sido apaixonadamente sublinhados...14

${ }^{14}$ Leonard Michaels, "Book Thieves and Philosophy", San Francisco Review of Books, May 1976 


\section{Conclusão: A ascensão do romance como crítica realista}

Os senhores sem dúvida devem estar se perguntando não apenas quando vou encerrar a palestra, mas também se vou encerrá-la usando A ascensão do romance como exemplo de como a filosofia deveria servir ao propósito dos estudos literários. A resposta é, receio eu, "sim"; mas somente no espírito de uma homilia de despedida cuja principal intenção é expressar minhas velhas ideias sobre o papel da crítica literária.

O relato que fiz sobre os verdes anos de confraternização com o pensamento alemão me livrará, espero, de qualquer rejeição carrancuda da filosofia enquanto tal. Presumo, é claro, que, como professores e acadêmicos, tenhamos a obrigação de procurar entender o máximo que pudermos acerca do mundo em que vivemos, mesmo quando isso às vezes se revele uma tentativa de entender mal-entendidos. Mas não creio que precisemos listar todos os nossos pressupostos em nossos textos e não vejo por que ensaiar uma defesa filosófica do velho juízo ingênuo de que todos sabemos muito bem o que é real e o que as palavras significam e como elas nos permitem falar de assuntos de interesse comum. É nesse sentido que vejo $A$ ascensão do romance como uma obra de crítica realista; e isso, suponho, está conectado com quatro aspectos do livro que valem ser comentados: sua atitude diante da filosofia, diante da linguagem, diante do leitor e diante do tema.

Filosoficamente assume-se que o realismo em geral considera o raciocínio dedutivo um guia menos confiável para a verdade do que a experiência comum. Isso sem dúvida mostra por que evito a maioria das questões metodológicas. Suponho que a filosofia pode ajudar o crítico de três maneiras, pelo menos: ela lhe dá uma ideia de como diferentes tipos de problemas podem ser abordados; fornece-lhe um senso de consistência conceitual e do apropriado grau de lógica em uma exposição; e, finalmente, por lhe fornecer uma noção da inter-relação entre diferentes corpora de conhecimento, o esforço, na expressão de Robert Louis Stevenson, de "circunavegar a metafísica" pode influenciar todo nosso modo de enxergar um determinado assunto. Enquanto examinava alguns ensaios antigos, interessei-me em saber o que Irving Howe escreveu sobre meu método em A ascensão do romance: "As várias escolas críticas das últimas décadas... vieram a unir-se... como elementos que foram assimilados pela sensibilidade do crítico... por exemplo... os insights emprestados a Marx tornaram-se coisa própria dele, inseparáveis de sua percepção como um todo". ${ }^{15}$

Sempre somos incomensuravelmente gratos aos críticos que nos ajudam a entender o que estávamos tentando fazer. A noção de Howe acerca da gestalt da percepção expressa perfeitamente o que eu senti, de modo intuitivo, naquela época, e hoje vejo com maior clareza, com relação ao valor básico da filosofia no enriquecimento da crítica literária; e esse valor, estou convencido, depende diretamente da capacidade das ideias envolvidas na promoção de nosso entendimento da experiência literária, estética e histórica.

${ }^{15}$ Irving Howe, "Criticism at Its Best”, Partisan Review, v. 25, p. 145, 1958. (N. do E.) 
A questão do apropriado decoro linguístico na crítica literária está intimamente associada a isso. Eu não diria que a terminologia filosófica tem nenhum status superior. É claro que todas as investigações mais ou menos especializadas têm seu próprio jargão; os encanadores fazem uma bela distinção entre junta e encadeamento; mas o vocabulário da crítica deve estar o mais próximo possível do senso comum em sua tentativa de produzir afirmações claras e acessíveis. Também deve evitar a abstração desnecessária como gentileza ao leitor e ao tema tratado. Lembro-me de uma conversa com Theodor Adorno quando, depois de eu ter contado o que havia feito aquela manhã (retirado alguns livros da biblioteca, ido à lavanderia etc.) e perguntado sobre seus afazeres, senti um ligeiro arrepio quando ele respondeu: "Tenho meditado sobre problemas eróticos e musicológicos".

O efeito dos vocábulos longos funciona um pouco como a impressão atribuída por Fowler à exata pronúncia das palavras francesas em inglês: "quanto maior o sucesso como tour de force, maior o fracasso para o andamento da conversa; pois seu interlocutor, ciente do fato de que ele próprio não teria conseguido atingir essa perfeição, se distrai pensando se deve ficar admirado ou sentir-se humilhado". ${ }^{16}$

Qualquer crítica literária cujo efeito é a humilhação do leitor (já vi casos em que esse parece ter sido o único intuito) a mim parece frustrar seu propósito primário, que é, penso, o de ser parte de uma conversa entre amantes da literatura. Nesse sentido, o cuidado do crítico por uma orientação comum com seu leitor no campo literário deve produzir um estilo de discurso fraterno; ou seja, um discurso cuja retórica implica uma posse equânime e comum de interesses e sentimentos compartilhados. Eu prezo algumas cartas e encontros casuais, aliás, que indicaram que minhas intenções a esse respeito não passaram despercebidas a certos leitores de A ascensão do romance.

Wittgenstein disse certa feita que não jantava nas mesas dos professores porque "as conversas não falavam nem ao coração nem ao cérebro". É delicado saber como o coração pode ser representado no texto crítico; mas certamente deve haver algum sinal de que a experiência do autor com a literatura perpassa as palavras que ele emprega e a maneira como as emprega. E a atitude "realista" para com a literatura também deve refletir, creio, o fato de que muitas gerações de seres humanos concederam à literatura, e às artes em geral, um lugar especial em seu coração, um lugar que os fez olhar com reverência, admiração ou um senso de dever pessoal na direção daqueles que tanto contribuíram para suas vidas e seu entendimento. Não é por acaso, suponho que posso dizer, que A ascensão do romance termine, se não estou enganado, com as palavras: "Defoe, Richardson e Fielding... [expressaram] sua própria visão da vida com uma plenitude e uma convicção muito rara e pela qual lhe somos gratos".

Como sou grato aos senhores por sua presença e sua paciência.

${ }^{16}$ Modern English Usage, v. French words. (N. do E.) 